\title{
The Neuro Image Quiz, Questions
}

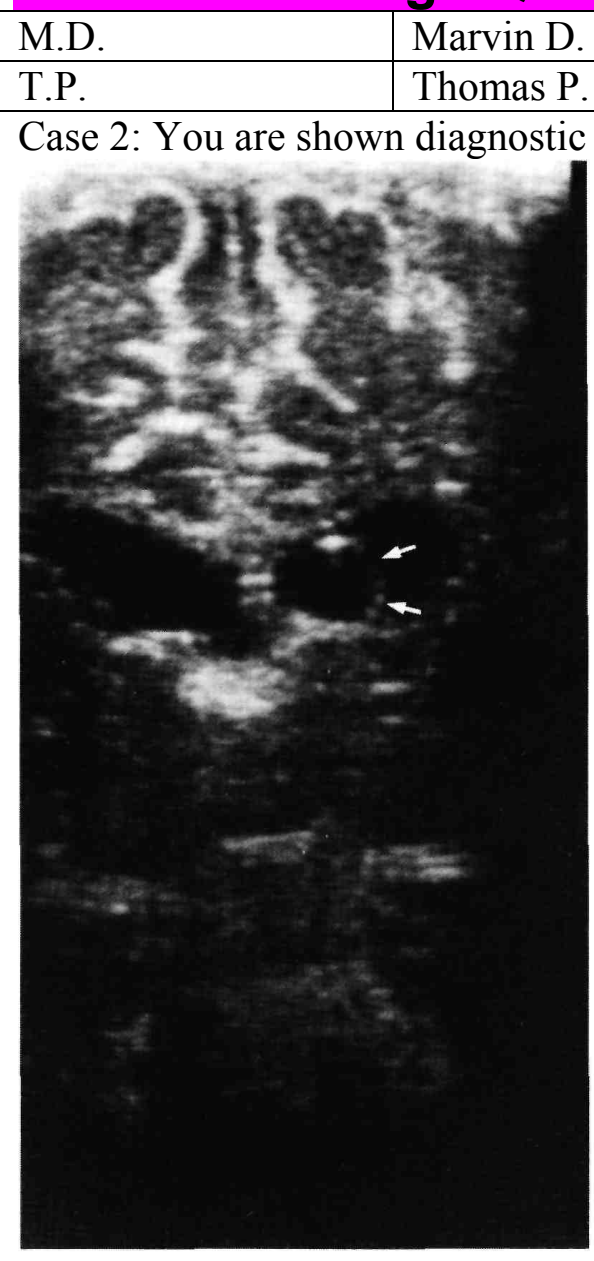

Nelson, Jr.

Naidich

Case 2: You are shown diagnostic images of a 5-month-old boy:

a Coronal sonogram via anterior fontanelle, $5-\mathrm{mHz}$ linear array transducer. b Sagittal sonogram via the anterior fontanelle, $5-\mathrm{mHz}$ sector transducer. Questions

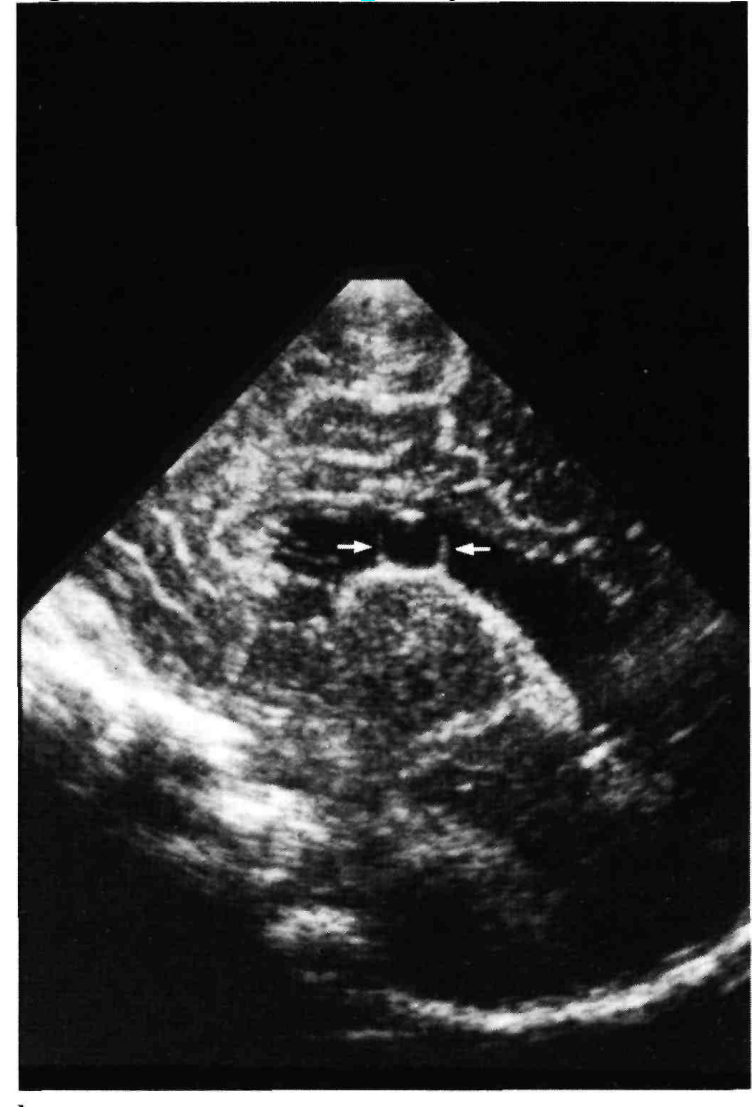


Use the right hand side for your personal notes.

What is the etiology of this patient's ventricular mass?

How common are such lesions?

How are these lesions usually detected?

Do the majority of cases of this entity require surgical therapy?

The answers to the questions appear on pp. 282-283 of this issue. 